\title{
Effect of Temperature on the Molecular Weight Distribution in the Different Ranks of Coal during the On-Line Investigation of Coal Pyrolysis Gas Using Direct Photoionization Mass Spectroscopy
}

\author{
Makhosazana Mthembu ${ }^{1,2}$, Ralf Zimmermann ${ }^{1,3}$, Thorsten Streibel1,3, Martin Sklorz ${ }^{1}$ \\ ${ }^{1}$ Joint Mass Spectrometry Centre, Chair of Analytical Chemistry, Institute of Chemistry, University of Rostock, \\ Rostock, Germany \\ ${ }^{2}$ Sasol Group Technology R\&T, Sasolburg, South Africa \\ ${ }^{3}$ Joint Mass Spectrometry Centre, Department of Comprehensive Molecular Analytics (CMA), Helmholtz \\ Zentrum München, Oberschleissheim, Germany \\ Email: Khosi.mthembu@sasol.com
}

Received 7 August 2015; accepted 27 December 2015; published 30 December 2015

Copyright (C) 2015 by authors and Scientific Research Publishing Inc.

This work is licensed under the Creative Commons Attribution International License (CC BY).

http://creativecommons.org/licenses/by/4.0/

(c) (9) Open Access

\begin{abstract}
Coal pyrolysis gas from different ranks of coal was monitored on real time basis using photoionization mass spectroscopy. The molecular weight distribution of different products as a function of temperature from various coal ranks studied was observed. It was noted that the release of different classes of compounds like phenols, alkenes, alkylated aromatics and aromatic skeletons was temperature dependent. For all the coal ranks at lower temperatures phenols were the main component, with alkenes and alkylated aromatics at slight higher temperatures and aromatic skeletons were released at the highest temperatures studied.
\end{abstract}

\section{Keywords}

Coal Ranks, Photoionization, Temperature Effect, Molecular Weight Distribution, Coal Pyrolysis Gas

\section{Introduction}

The chemical composition of coal liquefaction products is quite different from the conventional oil fractions obtained from crude oil. While classical petroleum fractions are usually rich in paraffinic compounds and in sulfur,

How to cite this paper: Mthembu, M., et al. (2015) Effect of Temperature on the Molecular Weight Distribution in the Different Ranks of Coal during the On-Line Investigation of Coal Pyrolysis Gas Using Direct Photoionization Mass Spectroscopy. International Journal of Clean Coal and Energy, 4, 69-80. http://dx.doi.org/10.4236/ijcce.2015.44007 
coal products are mainly composed of aromatic compounds, unsaturated species and heteroatom species (nitrogen, sulfur and oxygen-containing molecules). Properties of coal derived liquids are strongly influenced by the origin and the maturity of the parent coal. In fact, as geological processes apply pressure to the biological derived material, they successively transform into different ranks of coalification stages, namely lignite, sub-bituminous, bituminous and anthracite, which finally turn to graphite [1]. Lignite has a high moisture content compared to anthracite which is the highest rank in coal. Coal rank is one of the very important factors to consider for the advanced gasification processes. A coal that has high moisture and ash content is less efficient to gasify as it should be first heated to the reaction temperature and can affect the performance of the gasifiers [2].

Coal is usually studied by altering the structure with processes such as depolymerization and pyrolysis. Pyrolysis yields hydrocarbon gases that vary greatly depending on the characteristics of the parent coal. Thus pyrolysis behavior of coal is a strong function of coal type or rank. Low rank coals such as lignite and sub-bituminous coal produce relatively high levels of light gases and very little tar. Bituminous coals produce significantly more tar than lower rank coals and moderate amount of light gases. Higher rank coals produce relatively low levels of light gases and tar [3] [4].

Coal pyrolysis can yield useful chemical feedstock and constitutes also an intermediate step in clean coal conversion process of gasification [5] [6]. Gasification typically refers to the heterogeneous reactions that occur after pyrolysis has run its course [7]. The process mainly involves two steps: initial devolatilization (pyrolysis) produces gases, tar, and char; afterwards, subsequent gasification of the generated char takes place [3]. The efficiency of the gasification process and the gasification rate to full coal conversion in the single pass process depends on pyrolysis or devolatilization conditions. The amount of volatiles released during devolatilization is a function of coal structure. The rate of char gasification reactions is a function of the derived char properties. Increasing the process intensity without altering the reactors or gasifiers implies to provide insight into the impact of the devolatilization of coal. The chemical and physical structure of coal char varies significantly with coal rank and pyrolysis reaction conditions such as temperature, initial heating rate, and pressure [8]. Particle size of coal is one of the key variables as well. Pyrolysis temperature affects the composition of pyrolysis products from a coal as a result of the changes in the coal particle temperature and heating rate. Formation, vaporization and cross-linking of the tar and light gases are very dependent on temperature as well as heating rate as the results of the distribution of chemical bonds in coal with differing activation energies.

Coal is a complex substrate whose chemical composition varies with origin and age. Coal molecular structure, mass distribution and effects of pyrolysis conditions have been investigated using mass spectrometry of various ionization techniques including chemical ionization [9], field ionization (FI) [9]-[11], field desorption (FD) [9][12], fast bombardment (FAB) [9]-[13], laser desorption (LD) [14] [15], matrix-assisted laser desorption ionization (MALDI) [16]-[18] and electrospray ionization (ESI) [19] [20]. Most of these mentioned methods highly fragment the heavy components into volatiles and analyze complex mixtures offline such as FAB, MALDI and ESI. The advantage of direct mass spectrometry is their enabling the possibility to analyze such complex organic gas mixtures as derived from coal pyrolysis online. In this regard photo-ionization provides an alternative tool for the identification of the broad range of species with minimal fragmentation due to its inherent soft character. This method presents an opportunity to identify and quantify components such as PAH from bituminous coal soot in real time [21]. VUV photoionization has been successfully applied to study the volatiles species from bituminous coal [22]. In a recent study of our own the applicability of single photon ionization (SPI) and resonance enhanced multi photon ionization (REMPI) for the characterization of volatile and semivolatile species evolved during the pyrolysis of lignite at different temperatures has been demonstrated.

This new study aims to extend the previous one through investigation of coals of different ranks and their behavior under pyrolytic conditions. This should be achieved by studying the effect of temperature on the molecular weight distribution from different ranks of coal using pyrolytic decomposition analyzed by photo-ionization mass spectrometry.

\section{Experimental}

The experimental procedure has been described previously [23]. A brief description pertinent to the investigated samples studied in this publication is given in the following.

\subsection{Samples Investigated}

Three German coals comprising of lignite, flame coal and anthracite were studied in parallel to three bituminous 
South African coals, viz. gas flame coal with floating density of 2, gas flame coal with sinking density of 2 and fat coal, which is mostly used for liquid conversion. Particle size of all coals was less than $1 \mathrm{~mm}$ in diameter as the samples were grinded into fine powder. Elemental composition of the studied coals is given in Table 1. From lignite to anthracite the carbonaceous material and rank of coal increases.

\subsection{Analysis Equipment}

Pyrolysis VCI Oven: German VCI oven (Heraeus D-6450 Hanua type ROK/A3/30 S) was used for the devolatilization of the coal samples. The furnace has the capability of varying pyrolysis temperature. The oven design provides conditions for a sample size of approximately $100 \mathrm{mg}$, temperature variations from $200^{\circ} \mathrm{C}$ to $1000^{\circ} \mathrm{C}$ in two separately controlled heated zones, and variable carrier/reagent gas compositions and flow rates. The devolatilized products pass through the two hot zones in approximately 2 minutes.

REMPI-TOFMS: principle has been intensively discussed in the literature [24]-[27] ANd:YAG laser (10 ns pulse width, beam energy: $2.3 \mathrm{~mJ}$, repetition rate $10 \mathrm{~Hz}$ ) was used, providing photons with a wavelength of 266 $\mathrm{nm}$. The method provides efficient ionization, particularly for aromatic compounds using one-photon resonant/ two-photon ionization process. The first photon is absorbed, and elevates the molecule to an excited state, from which the second photon is absorbed to ionize the relevant molecule. The second photon ionization cross-section is enhanced considerably when the first photon energy is in the resonance absorption step of the analyte. Laser ionization with a pulsed laser is ideal suited for the combination with time-of-flight mass spectrometry (TOFMS), allowing the registration of the total mass spectrum with every laser shot Reflectron CTF10 TOFMS.

SPI-TOFMS: was used to detect all compounds with an ionization energy below the applied $126 \mathrm{~nm}$ photon energy $(9.8 \mathrm{eV})$, giving an on-line overview about the chemical composition of the evolved coal pyrolysis gases. SPI method uses a single photon for soft ionization which is well suited for detection of both aromatic and aliphatic compounds. VUV photons were generated by means of an electron beam pumped rare gas excimer VUV lamp technology (EBEL). This continuous VUV beam is focused in the ionization source of an orthogonal TOFMS (C-TOF, TOFWERK AG, Thun, Switzerland). This type of TOFMS is best suited for continuous light sources such as the EBEL VUV lamp because of the pulsed orthogonal extraction at high repetition rates $(>10000 \mathrm{~Hz})$ (Figure 1).

Standard: REMPI- and SPI-TOFMS were both calibrated by an external standard of $10 \mathrm{ppm}$ gas mixture of benzene; toluene, benzaldehyde and trimethylbenzene before and after the measurements were taken.

\subsection{Experimental Method}

$20 \mathrm{mg}$ sample was loaded on the sample inlet of the quart tube inserted inside the oven. The sample was allowed to stand in the inlet for 3 - 5 minutes to purge the system with nitrogen at $100 \mathrm{ml} / \mathrm{min}$ as inert gas. The sample was released and pyrolyzed under different temperatures from $400^{\circ} \mathrm{C}-800^{\circ} \mathrm{C}$ with increments of $50^{\circ} \mathrm{C}$ at constant nitrogen flow of $100 \mathrm{ml} / \mathrm{min}$. A fresh sample $(20 \mathrm{mg}$ ) was used at each selected temperature and the coal pyrolysis gas was passed through quartz wool to remove particulates. The clean pyrolysis gas produced was analyzed in real time by SPI- or REMPI-TOFMS. The pyrolysis gas was guided via a heated inert quartz capillary to the ion source of the mass spectrometers. The heating avoids condensation of heavy compounds within the tubes.

Table 1. Coal rank percentage of elementary carbon, hydrogen and oxygen.

\begin{tabular}{|c|c|c|c|c|}
\hline Coal rank & Abbreviation & \% Carbon & \% Hydrogen & \% Oxygen \\
\hline Lignite & BNK & 70 & 6 & 34 \\
\hline Sub-bituminous coal & FLK & 75 & 6 & $>9.8$ \\
\hline Gas flame coal $^{*}$ & WBF & 84 & 6.23 & 7.6 \\
\hline Gas flame coal & WBS & 84 & 6.23 & 7.6 \\
\hline Fat coal & SEC & 88 & 4.5 & 2.8 \\
\hline Anthracite & - & 94 & 3 & 2 \\
\hline
\end{tabular}

\footnotetext{
*Gas flame coal WBF differ from WBS coal on the content of inorganics and ash (not investigated in the project).
} 


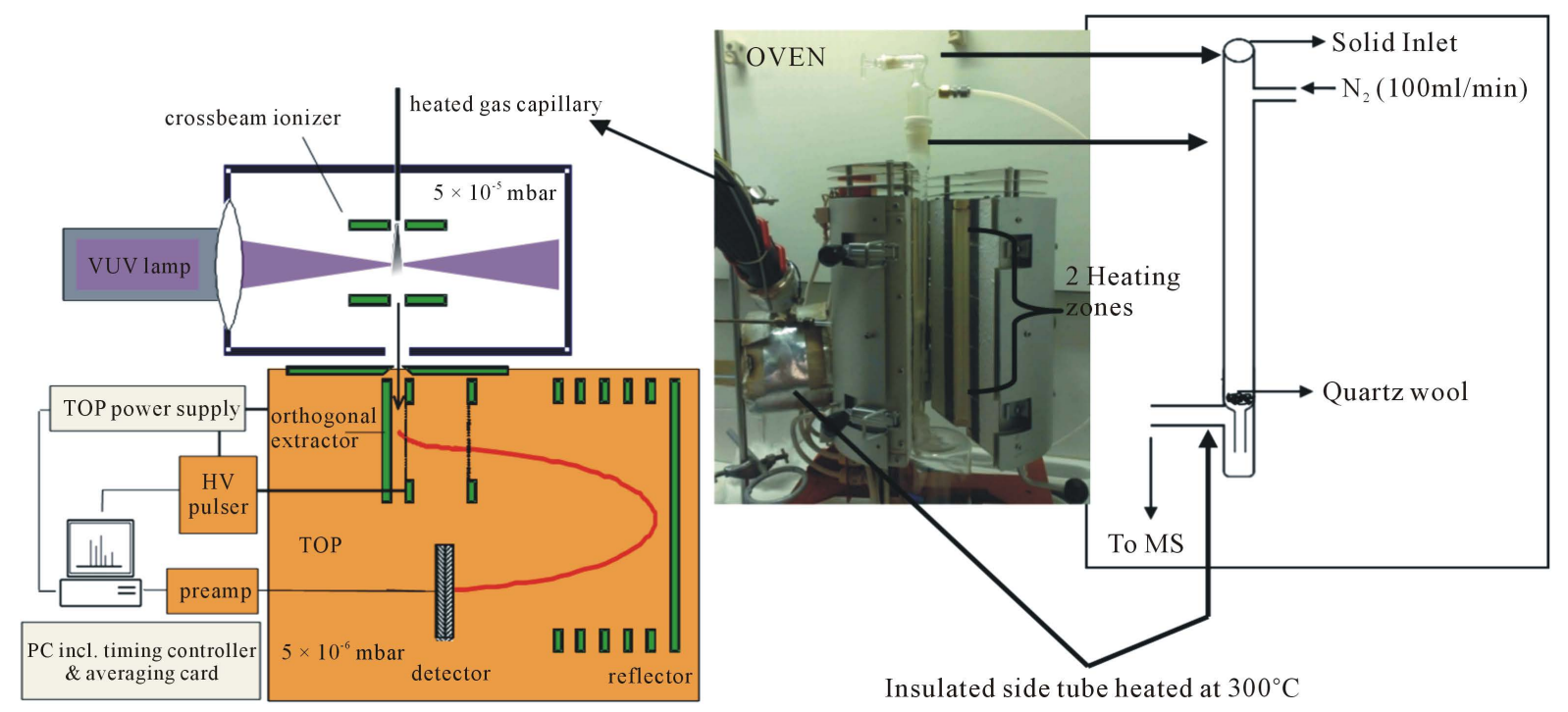

Figure 1. Schematic diagram of the experimental setup.

\section{Results and Discussion}

Characterization of pyrolysis products of different coal ranks using SPI-TOFMS and REMPI-TOFMS at different temperatures revealed the presence of both small volatile hydrocarbons and PAH. No detectable compounds were obtained for anthracite on the studied temperatures as a result of its carbon-rich structure. In the mentioned previous study, active thermal decomposition of coal could be viewed best at $650^{\circ} \mathrm{C}$. Figure 2 depicts the respective SPI-TOFMS spectra of all investigated coals at this temperature. It shows that lignite type coals (BNK) decomposes to smaller compounds compared to the bituminous type coal (WBS, WBF, SEC) as there are no species visible above $250 \mathrm{~m} / \mathrm{z}$ in the former. This demonstrates its higher content of volatile matter.

The distribution and the amount of phenolic compounds in coal and coal derived liquids have been indicated to play a role in aging reactions of coal liquefaction products, coal degradation and stability [28]. Phenol, cresol and xylenol content, Table 2 (referred to as PCX content) represents the most intense compounds in all coal ranks at this temperature, albeit there are slight differences in the signal distribution of different coals.

It was observed that cresol signal percentage (referred to total ion count of PCX) is $\geq 44 \%$ in the black coals, while with lignite it is accounted for $37 \%$. On the other hand, phenol amounts to $46 \%$ with lignite, whereas phenol in black coal is $25 \%$, half the amount of phenol in lignite. Higher phenol percentage in lignite can be as a result of thermal decomposition of alkylated phenols such as cresol and xylenol at temperature $650^{\circ} \mathrm{C}$. However not only volatilization of phenol already existing in lignite contributed. Cleavage of weak C-C and CO due to thermal cracking of oxygen containing structures such as carboxylic acid, ester and ether linkages, connecting condensed aromatic and hydroaromatic macromolecular structures occurred. Black coal is known to consist of phenolic hydroxyl as the main O-containing functional group and higher degree of condensed aromatic rings. Hence the amounts of phenols generated in lignite seem to be dependent on the properties of coal [29].

Alkenes in both low and high ranks of coal start at the molecular mass 42 (propene) with significant amount of $m / z 54$ and 56 (butadienes and butenes, respectively). In WBS coal alkenes ( $m / z$ 42, 54, 56) are more intense compared to all the other studied coals.

In contrast, SEC in the same rank as WBS revealed the less intensity in the low molecular weight alkenes. The difference of WBS compared to the other coal is high density which is usually associated with the other parameter that can play a role in molecular distribution that is large quantities of mineral matter.

The large amount of minerals is known to promote smaller fragments as minerals do not expand at the same rate as organic constituents of coal. This leads to internal stress in the coal particles, which results in the particles breaking up into smaller fragments [30].

Higher molecular weight signals are more difficult to assign, because many isobaric compounds are eligible. For example $\mathrm{m} / \mathrm{z} 158$ could represent C3 alkylated indenes or C5-alkylated benzenes. An interesting observation succeeded with the WBS coal, as the adsorbed flotation solvent (dibromoethene and tribromoethene) was also 
Table 2. PCX content in signal percentages at the temperature of $650^{\circ} \mathrm{C}$.

\begin{tabular}{ccc}
\hline Component & Lignite (BNK) & Black coals (WBS, WBF, SEC) \\
\hline Phenol & $46 \%$ & $25 \%$ \\
Cresol & $37 \%$ & $44 \%$ \\
Xylenol & $17 \%$ & $31 \%$ \\
\hline
\end{tabular}

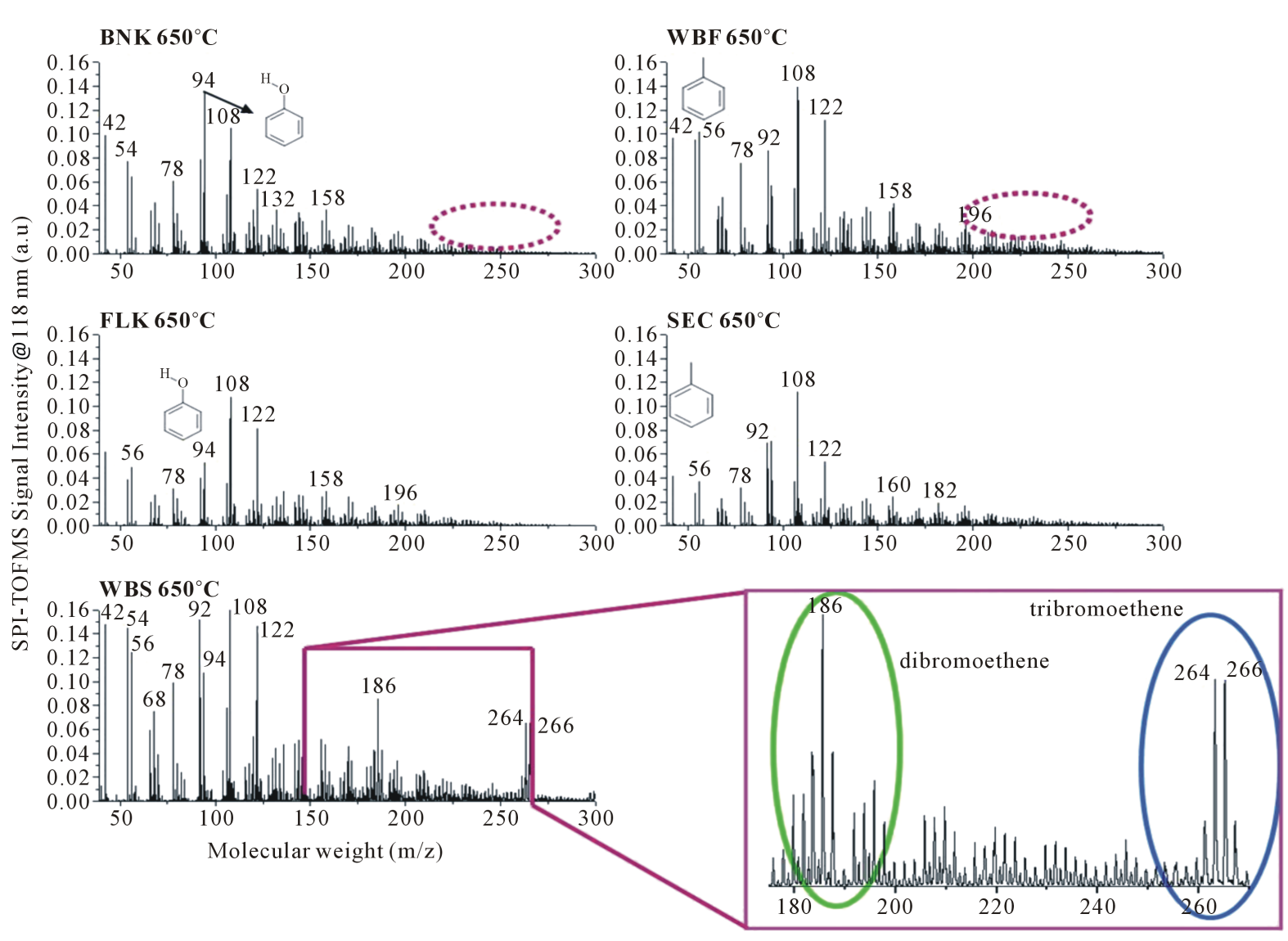

Figure 2. SPI-TOFMS spectra of different coal ranks at $650^{\circ} \mathrm{C}$.

detected and the peaks ( $\mathrm{m} / \mathrm{z} 186$ and 264) were the first to elute before the pyrolysis products. The identification is verified by the typical isotopic pattern of bromine containing species.

REMPI-TOFMS spectra, Figure 3 at the temperature of $650^{\circ} \mathrm{C}$ revealed mostly alkylated PAH. Phenols can be also detected with a very low intensity due to less efficient photo-ionization of single ring aromatics at the wavelength of $266 \mathrm{~nm}$.

High peak overlap was observed due to thermal decomposition combined with the high sensitivity of REMPITOFMS for detecting the PAH makes the interpretation of REMPI-TOFMS spectra often difficult, when looking at distinct molecular structures. However, single to 5-membered rings were observed in the form of homologue rows of alkylated PAH. Alkylated phenanthrenes were well-defined in all coals and also phenanthrene $(178 \mathrm{~m} / \mathrm{z})$ in SEC and WBS coals. Note that the isomeric anthracene is not detected under the chosen analytical conditions, since its ionization cross section is negligible compared to that of phenanthrene. Hydroaromatics e.g., dihydropyrenes were observed in all coal ranks and more highly alkylated peaks in BNK, FLK and WBF coals were identified. Longer chain substituted $\mathrm{PAH}$ in the high coal rank were observed at this temperatures $\mathrm{C}_{10}-\mathrm{C}_{13}$ alkylnaphthalenes ( $\mathrm{m} / \mathrm{z}$ 268, 282, 296 and 310); $\mathrm{C}_{10}$ alkylphenanthrene $(\mathrm{m} / \mathrm{z} 318)$ and $\mathrm{C}_{6}$ alkyl-benzopyrenes $(\mathrm{m} / \mathrm{z}$ 336). The longer chain can be the products from Diels-Alder and concerted reactions during the thermal decomposition of the different coal ranks. In conclusion, production of PAH increase with rank. The lower ranked 


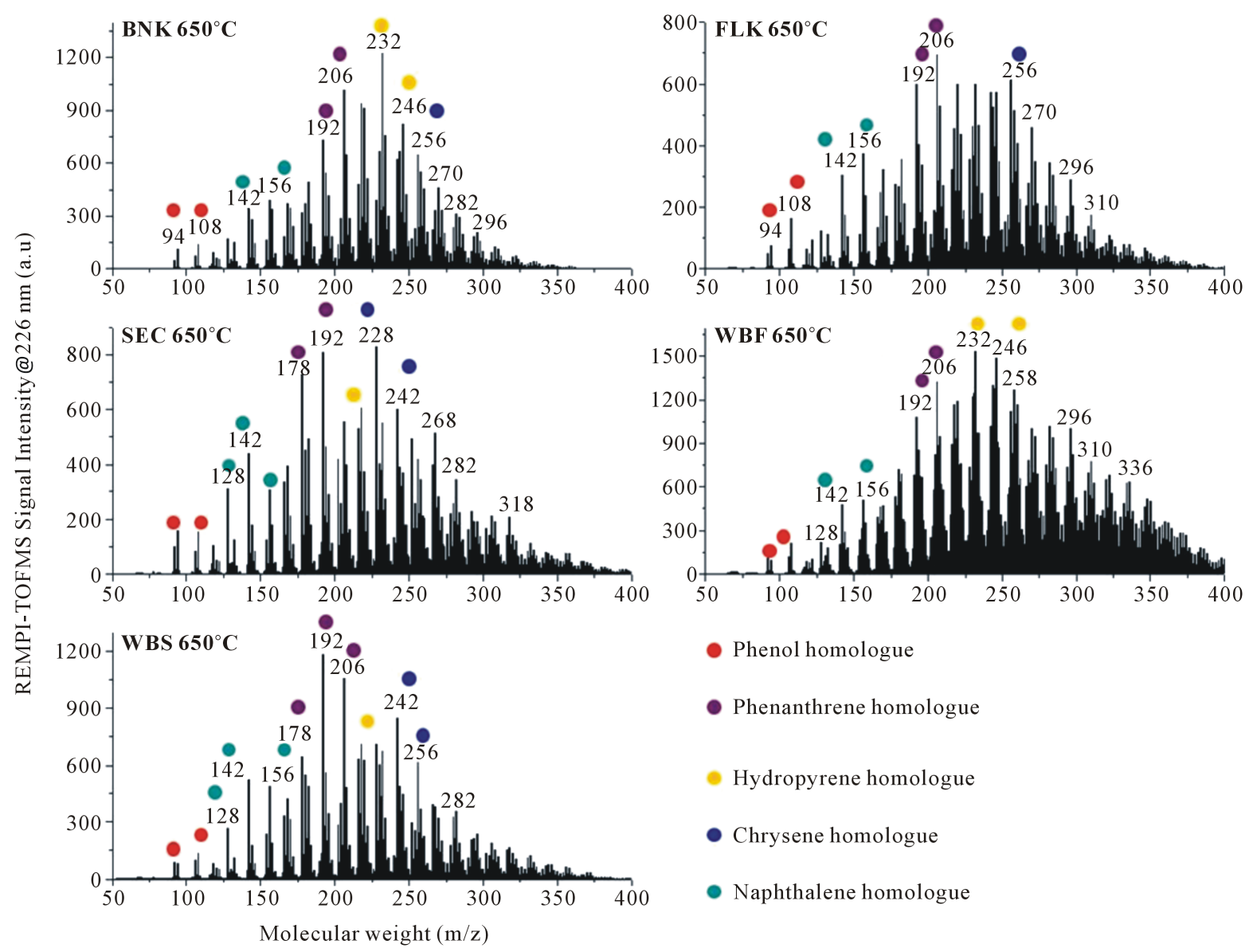

Figure 3. REMPI-TOFMS spectra of different ranks of coal at $650^{\circ} \mathrm{C}$.

coals, especially lignite, produce more oxygenated compounds and a reduced variety of PAH. Decomposition of WBF coal generates a large variety of PAH with molecular masses up to $400 \mathrm{~m} / \mathrm{z}$. The heavy coal WBS tends to behave more like a lower rank coal, producing more phenolic compounds and lower molecular weight PAH confirming the catalytic effect of the minerals. SEC high carbon content black coal generates less volatile matter i.e. less phenolic species and PAH compared to $\mathrm{WBF}$ at $650^{\circ} \mathrm{C}$. High volatility of the low rank coal BNK and WBS might resolve to high porosity char which provides more active sites for gasification reactions. SEC higher rank coal exhibiting higher aromaticity has a possiblity of forming chars with less surface area and ordered carbon lattice structure that may lead to fewer sites on which gasification can take place.

Principal component analysis was investigated for the molecular weight distribution as a function of temperature in different ranks of coal.

The first principal component describes the influence of temperature on the variance of the pyrolysis product patterns, which is the comprehensible main influential factor. The variance originating from different coal ranks is explained by the second principal component, however, it is much less pronounced. The loading plots disclose the opportunity to investigate, how the temperature dependency of certain substance classes behave with respect to their appearance in the pyrolysis gas. With SPI-TOFMS Figure 4 phenols were the first and major coal products released at lower temperatures of $400^{\circ} \mathrm{C}-700^{\circ} \mathrm{C}$ in the different coal ranks with an exception of up to $650^{\circ} \mathrm{C}$ for both lignite coal and WBS. For the high volatile matter comprising lignite, benzene and alkenes were already the main produced compounds at $700^{\circ} \mathrm{C}$ with lower concentration phenolic structure. Therefore thermal decomposition of lower rank coal occurs at lower pyrolysis temperature in comparison to black coal as a result of lower carbon content and the abundance of thermal labile groups. The macromolecular network is more stable and the labile bridges are progressively removed when coal rank increases. As a consequence, the volatile matter content decreased and the characteristics temperatures shift to higher values with increasing rank [31]. 

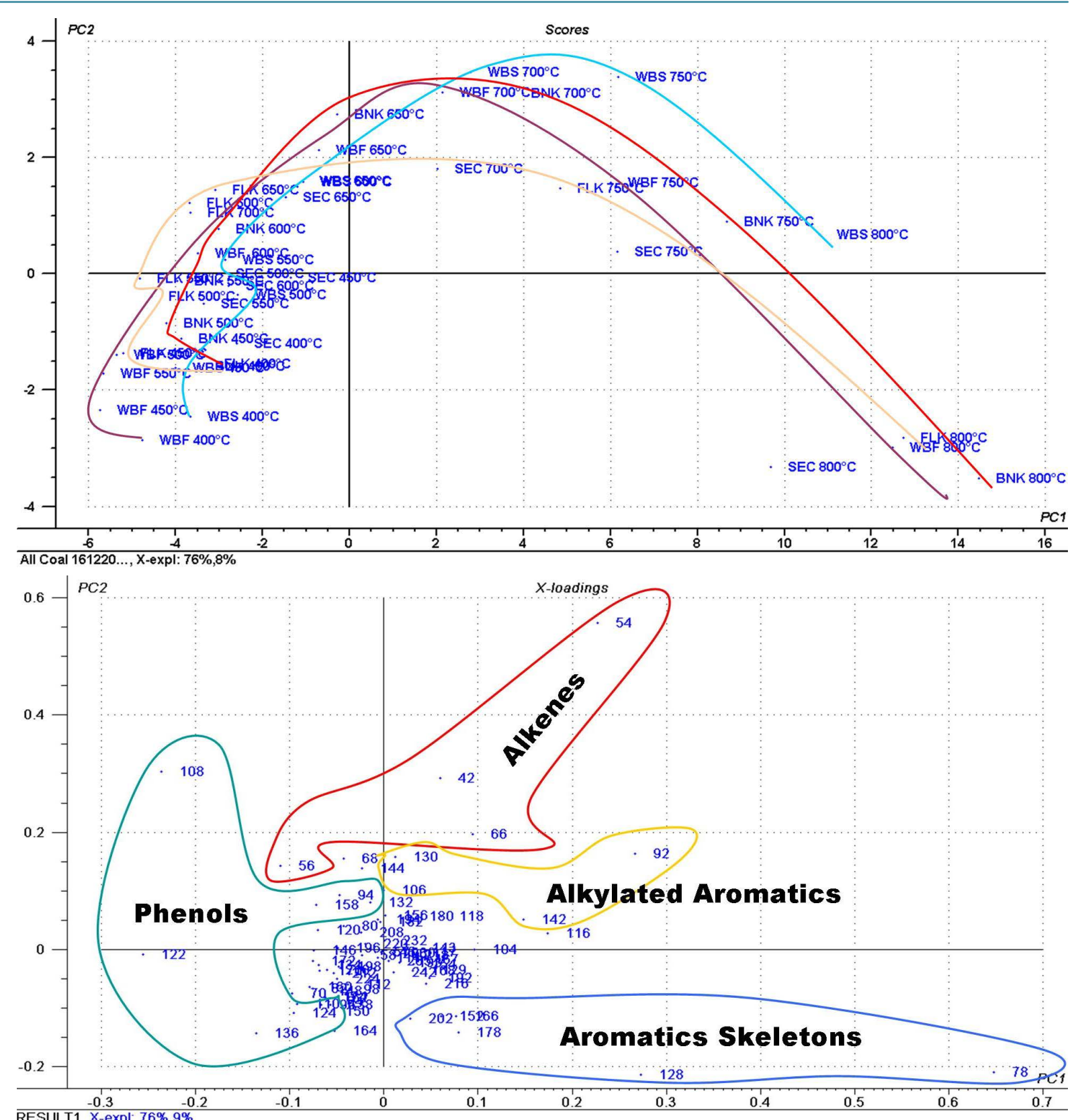

RESULT1. X-expl: $76 \% .9 \%$

Figure 4. Principal component analysis of significant masses in SPI-TOFMS.

Alkenes which are known to be high temperature gaseous products of the released alkyl side chains are mainly observed between temperatures of $700^{\circ} \mathrm{C}-750^{\circ} \mathrm{C}$ together with less alkylated aromatics such as toluene $(\mathrm{m} / \mathrm{z}$ 92) and methylnaphthalene $(\mathrm{m} / \mathrm{z}$ 142). The reason for the shorter chains of alkenes to show high loadings at the specified temperature is owing to the decomposition of saturated hydrocarbons and larger olefins $\left(C_{17}-C_{22}\right)$ to generate small molecular compounds. At the highest temperature of $800^{\circ} \mathrm{C}$ all coal ranks produce stable aromatics such as benzene, naphthalene, phenanthrene and pyrene, since chemical reactions always move in the direction of the most stable species, when the temperature increases which in this case are the non-alkylated aromatic ring systems.

Benzene was practically the most varying compound in all the coal ranks at high temperatures, this can be attributed to concerted reactions which involve simultaneous rupturing (and forming) of more than one bond. Based on the explanation of the formation of $\mathrm{CO}$ at high temperatures, one typical reaction scheme involved si- 
multaneous reaction of hydrogen radical with cresols to form a seven-membered ring which later reacts with hydrogen radicals to form benzene and $\mathrm{CO}$ [32]. This may possibly be the reason benzene is the most dominant pyrolysis product compound in the SPI-TOFMS spectra at $800^{\circ} \mathrm{C}$, and why cresols (o-cresol) are the main phenolic compound at the othertemperatures.

Cresols were observed as one of the main compounds in all coal ranks and also particularly featured in FLK and $\mathrm{WBF}$ at the temperature of $750^{\circ} \mathrm{C}$. In general, there are many similarities in the molecular decomposition pattern of the different ranked coals.

Nevertheless, there were some slight differences which could be observed, e.g. toluene $(\mathrm{m} / \mathrm{z}$ 92) representing one of the main compounds in the black coal at $600^{\circ} \mathrm{C}$.

REMPI-TOFMS Figure 5 with photon wavelength of $266 \mathrm{~nm}$ is highly sensitive for the detection of aromatic compounds even in low concentrations. In view of the fact that coal comprises of large aromatic structures it
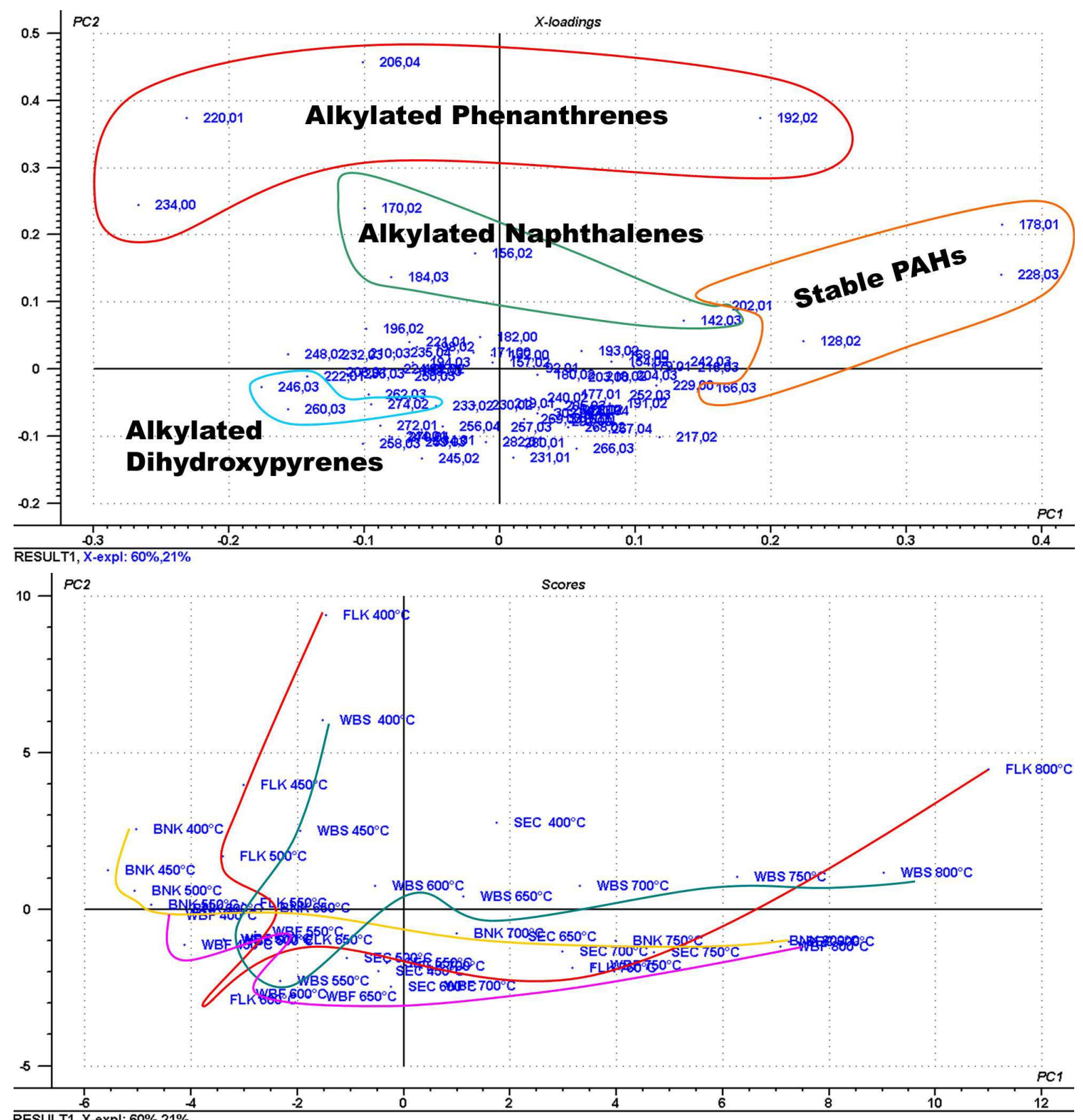
was a method of preference for studying the molecular weight spread of the aromatics in the different ranks of coal. Different homologous series were observed resembling alkylated phenanthrenes, naphthalenes, dihydropyrenes, and stable aromatic skeletons up to approximately six-membered rings. In the previous studies aromatics have been observed to retain their structures at temperatures as high as $700^{\circ} \mathrm{C}$ and NMR studies also revealed that the release of the alkyl side chain is highly dependent on the aromatic skeleton even when the aromatic content is as low as $40 \%$ as they are in sterically hindered positions [33]. This leads to steady dealkylation of the alkyl side chain from lower temperatures to high temperatures.

At temperatures between $400^{\circ} \mathrm{C}-700^{\circ} \mathrm{C}$ alkylated phenanthrenes were observed to be the most dominant PAH in all ranks of coal with retene $(\mathrm{m} / \mathrm{z} 234)$ and dihydroxypyrenes $(\mathrm{m} / \mathrm{z} 232)$ as most important compounds in the lignite coal. Increase in aromaticity with the high rank of coal was observed with the presence of chrysene $(\mathrm{m} / \mathrm{z} 228)$ in SEC coal at a temperature as low as $550^{\circ} \mathrm{C}$. The significance of methylphenanthrene $(\mathrm{m} / \mathrm{z} 192)$ in the high rank of coal was examined to increase and intensify with the increase in temperature.

In Figure 6 coal pyrolysis gas is known as source of individual chemicals as well as fraction of classes of chemical mixtures. Hence; alkenes, phenols, alkyl aromatics and stable aromatics are all classes that were identified in all coal ranks with different intensities at the studied temperatures. In all coal ranks alkenes exhibited a maximum at the temperature of $700^{\circ} \mathrm{C}$, whereas with phenolic species the location of the maximum is depending on the rank and temperature, respectively. Phenol $(\mathrm{m} / \mathrm{z}$ 94) concentration is highest at a thermal decomposition temperature of $650^{\circ} \mathrm{C}$ in the lignite coal (BNK), $600^{\circ} \mathrm{C}$ in FLK and WBS, $700^{\circ} \mathrm{C}$ in SEC and WBF. For cresols $\left(\mathrm{m} / \mathrm{z}\right.$ 108), basically SEC and WBF differ from the other coals, as the optimal temperature for cresol is $700^{\circ} \mathrm{C}$, whereas the other coals exhibit earlier and broader maximum concentration levels as a function of temperature. Alkylated aromatics and stable aromatics had similar trends in all coal ranks. They show a gradually increase with temperature up to $750^{\circ} \mathrm{C}$; afterwards WBF and BNK tend to decrease, whereas SEC and FLK are still rising. WBS shows relatively low concentrations throughout, that are not severely affected by temperature. The trend for stable aromatics is also similar with every coal, again depicting a steady increase with pyrolysis temperature.
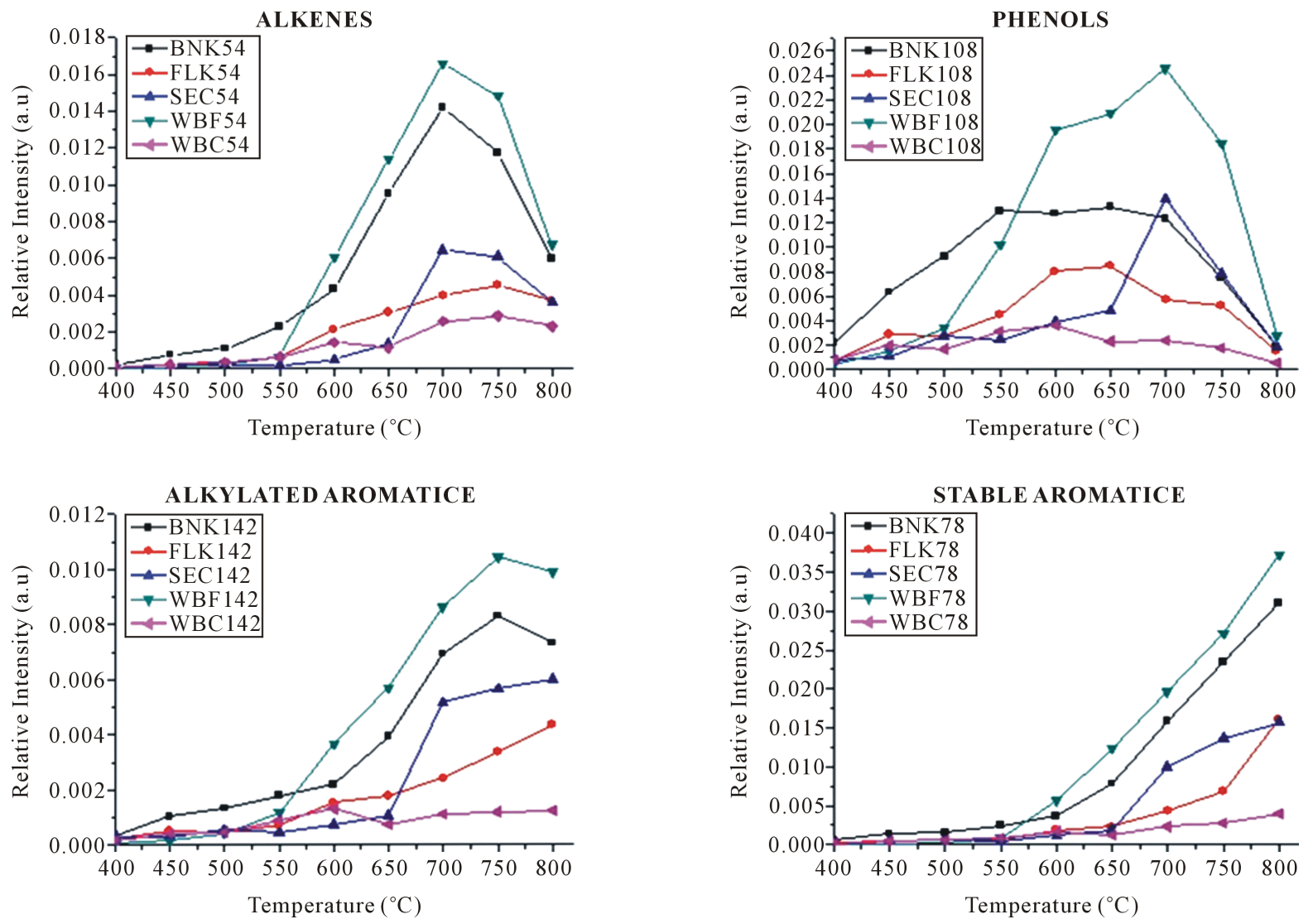

Figure 6. Trends of alkenes, phenols, alkylated aromatics, stable aromatics from the studied coal rank. 
As with the alkylated aromatic species, WBF and BNK show the highest concentration levels, and WBS produces relatively low amounts. This is consistent with the behavior of aliphatic and phenolic decomposition products, which show roughly the same tendencies. The pyrolysis behavior of all high rank coal resembles vitrinite-rich bituminous coal rich in oxygen with the amount of oxygen approximately equivalent to that contained in low rank coal. These coals are known to soften during pyrolysis and expand to form cellular structures, which increase the internal surface area resulting in a porous char [34].

\section{Conclusions}

Temperature and coal rank have a great effect on the coal pyrolysis gas product composition and the molecular weight distribution. SPI-TOFMS and REMPI-TOFMS provided insight on the composition of the coal pyrolysis gas from low molecular weight compounds to higher molecular weight alkylated PAH. Analysis of coal pyrolysis gas products yielded some information on the structure of parent coal that can be useful for coal processing, especially since many structural units of coal are known to be released into the coal pyrolysis gas. In all coal ranks phenols are the main component of the pyrolysis gas at lower temperatures however they are present in different signal intensity percentages at different temperatures. It was also observed that at the highest temperature studied in both techniques the pyrolysis products produced are similar in all the ranks of coal, albeit varying in concentration.

High volatile content was observed in all coals and had an impact on the properties of the chars formed during pyrolysis. This is because the evolution of volatile matter from the coal particles affects the porosity of the formed char and thus influences the overall char reactivity. This is valid, as gasification is a solid-gas reaction and dependent on the available char surface area. In general low rank coal chars will have higher gasification reactivity than the higher rank coal. This fact is a result of their different carbon content. The degree of aromatization in the coal structure increases with the increase in the rank of coal and the complexity of the aromatization decide the gasification rate [35].

\section{Acknowledgements}

The project was financially supported by Sasol Group Technology R\&T in South Africa and was conducted in University of Rostock facilities in Germany. Technical and scientific support was supplied by AloisFendt.

\section{References}

[1] Badaoui, O., Marion, C., Nadége, C., Didier, T.T. and Alain, Q. (2010) Characterization of Oxygenated Species in Coal Liquefaction Products. Energy \& Fuels, 24, 5807-5816. http://dx.doi.org/10.1021/ef100894n

[2] Crnomarkovic, N., Repic, B., Mladenovic, R., Neskovic, O. and Veljkovic, M. (2007) Experimental Investigation of Role of Steam in Entrained Flow Coal Gasification. Fuel, 86, 194-202. http://dx.doi.org/10.1016/j.fuel.2006.06.015

[3] Zhang, D. (2004) Thermal Decomposition of Coal. http://www.eolss.net/sample-chapters/c08/E3-04-03-02.pdf

[4] Freihaut, J.D., Proscia, W.M. and Seery, D.J. (1989) Chemical Characteristics of Tar Produced in a Novel Low Severity, Entrained-Flow Reactor. Energy \& Fuels, 3, 692-703. http://dx.doi.org/10.1021/ef00018a006

[5] Wang, S., Tang, Y., Schobert, H.H., Guo, Y., Gao, W. and Lu, X. (2013) FTIR and Simultaneous TG/MS/FTIR Study of Late Permian Coals from Southern China. Journal of Analytical and Applied Pyrolysis, 100, 75-80. http://dx.doi.org/10.1016/j.jaap.2012.11.021

[6] Safarova, M., Kusy, J. and Andel, L. (2005) Pyrolysis of Brown Coal under Different Process Conditions. Fuel, 84, 2280-2285. http://dx.doi.org/10.1016/j.fuel.2005.05.015

[7] Chen, H., Yang, H., Ju, F., Wang, J. and Zhang, S. (2007) The Influence of Pressure and Temperature on Coal Pyrolysis/Gasification. Asia-Pacific Journal of Chemical Engineering, 2, 203-212. http://onlinelibrary.wiley.com/doi/10.1002/apj.42/abstract http://dx.doi.org/10.1002/apj.42

[8] Van Heek, K.H. and Muhlen, H.J. (1987) Effect of Coal and Char Properties on Gasification. Fuel Processing Technology, 15, 113-133. http://dx.doi.org/10.1016/0378-3820(87)90039-7

[9] Herrod, A.A., Stokes, B.J. and Schulten, H.R. (1993) Coal Tar Analysis by Mass Spectrometry a Comparison of Methods. Fuel, 72, 31-43. http://dx.doi.org/10.1016/0016-2361(93)90372-9

[10] Schulten, H.R. (1992) Mass Spectrometric and Chemometric Studies of Thermoplastic Properties of Coals. 2. Field Io- 
nization Mass Spectrometry of Coals. Energy \& Fuel, 6, 103-108. http://dx.doi.org/10.1021/ef00031a015

[11] Wang, X.M., Marzec, A. and Schulten, H.R. (1989) Coal Characterization by On-Line Pyrolysis-Field Ionization Mass Spectrometry. Fresenius' Zeitschrift für Analytische Chemie, 333, 793-799.

[12] Schulten, H.R. (1982) Pyrolysis-Field Desorption Mass Spectrometry of Coal. Fuel, 61, 670-676. http://dx.doi.org/10.1016/0016-2361(82)90015-1

[13] Herrod, A.A., Stokes, B.J., Tye, R.E., Gaines, A.F. and Li, C.Z. (1993) Comparison of Fast Atom Bombardment Mass Spectrometry and Size Exclusion Chromatography in Defining High Molecular Masses in Coal-Derived Materials. Fuel, 72, 1317-1325. http://dx.doi.org/10.1016/0016-2361(93)90131-K

[14] Parker, J.E., Johnson, C.A.F., John, P., Smith, G.P., Herod, A.A., Stokes, B.J. and Kandiyoti, R. (1993) Identification of Large Molecular Mass Material in High Temperature Coal Tars and Pitches by Laser Desorption Mass Spectroscopy. Fuel, 72, 1381-1391. http://dx.doi.org/10.1016/0016-2361(93)90414-W

[15] Janitschke, W., Möller, U., Uherek, E. and Kleinermanns, K. (2000) Investigations of Coals by On-Line Coupled Laser Desorption/Gas Chromatography/Mass Spectrometry (LD/GC/MS). Journal of Analytical and Applied Pyrolysis, 56, 99-111. http://dx.doi.org/10.1016/S0165-2370(00)00086-3

[16] Domin, M., Li, S., Lazaro, M.J., Herod, A.A., Larsen, J.W. and Kandiyoti, R. (1998) Large Molecular Mass Materials in Coal-Derived Liquids by 252Cf-Plasma and Matrix-Assisted Laser Desorption Mass Spectrometry. Energy \& Fuel, 12, 485-492. http://pubs.acs.org/doi/abs/10.1021/ef970131u

[17] Herod, A.A., Lazaro, M.J., Domin, M., Islas, C.A. and Kandiyoti, J. (2000) Molecular Mass Distributions and Structural Characterisation of Coal Derived Liquids. Fuel, 79, 323-337. http://dx.doi.org/10.1016/S0016-2361(99)00167-2

[18] George, A., Morgan, T.J., Alvarez, P., Millan, M., Herod, A.A. and Kandiyoti, R. (2010) Fractionation of a Coal Tar Pitch by Ultra-Filtration, and Characterization by Size Exclusion Chromatography, UV-Fluorescence and Laser Desorption-Mass Spectroscopy. Fuel, 89, 2953-2970. http://dx.doi.org/10.1016/j.fuel.2010.04.011

[19] Wu, Z., Jernström, S., Hughey, C.A., Rodgers, R.P. and Marshall, A.G. (2003) Resolution of 10000 Compositionally Distinct Components in Polar Coal Extracts by Negative-Ion Electrospray Ionization Fourier Transform Ion Cyclotron Resonance Mass Spectrometry. Energy \& Fuels, 17, 946-953. http://pubs.acs.org/doi/abs/10.1021/ef030026m

[20] Kim, S., Rodgers, R.P., Blakney, G.T., Hendrickson, C.L. and Marshall, A.G. (2009) Automated Electrospray Ionization FT-ICR Mass Spectrometry for Petroleum Analysis. Journal American Society Mass Spectrometry, 20, $263-268$. http://link.springer.com/article/10.1016\%2Fj.jasms.2008.10.001

[21] Gao, S., Zhang, Y., Meng, J. and Shu, J. (2009) Real-Time Analysis of Soot Emissions from Bituminous Coal Pyrolysis and Combustion with a Vacuum Ultraviolet Photoionization Aerosol Time-of-Flight Mass Spectrometer. Science of the Environment, 407, 1193-1199. http://dx.doi.org/10.1016/j.scitotenv.2008.10.026

[22] Jia, L., Weng, J., Wang, Y., Sun, S., Zhou, Y. and Qi, F. (2013) Online Analysis of Volatile Products from Bituminous Coal Pyrolysis with Synchrotron Vacuum Ultraviolet Photoionization Mass Spectrometry. Energy \& Fuels, 27, 694 701.

[23] Kiersch, K., Kruse, J., Eckhardt, K.-U., Fendt, A., Streibel, T., Zimmermann, R., Broll, G. and Leinweber, P. (2012) Impact of Grassland Burning on Soil Organic Matter as Revealed by a Synchrotron- and Pyrolysis-Mass SpectrometryBased Multi-Methodological Approach. Organic Geochemistry, 44, 8-20. http://dx.doi.org/10.1016/j.orggeochem.2011.12.002

[24] Zimmermann, R., Heger, H.J. and Kettrup, A. (1999) On-Line Monitoring of Traces of Aromatic-, Phenolic- and Chlorinated Components in Flue Gases of Industrial Scale Incinerators and Cigarette Smoke by Direct-Inlet Laser Ionization-Mass Spectrometry (REMPI-TOFMS). Journal of Analytical Chemistry, 363, 720-730. http://dx.doi.org/10.1007/s002160051281

[25] Zimmermann, R., Heger, H.J. and Kettrup, A. (2000) Direct Observation of the Formation of Aromatic Pollutants in Waste Incineration Flue Gases by On-Line REMPI-TOFMS Laser Mass Spectrometry. Journal of Analytical Chemistry, 366, 368-374. http://dx.doi.org/10.1007/s002160050075

[26] Heger, H.J., Zimmermann, R., Dorfner, R., Beckmann, M., Griebel, H., Kettrup, A. and Boesl, U. (1999) On-Line Emission Analysis of Polycyclic Aromatic Hydrocarbons Down to PPTV Concentration Levels in the Flue Gas of an Incineration Pilot Plant with a Mobile Resonance-Enhanced Multiphoton Ionization Time-of-Flight Mass Spectrometer. Analytical Chemistry, 71, 46-57. http://dx.doi.org/10.1021/ac980611y

[27] Mühlberger, F., Wieser, J., Uldrich, A. and Zimmermann, R. (2002) Single Photon Ionization (SPI) via Incoherent VUV-Excimer Light: Robust and Compact Time-of-Flight Mass Spectrometer for On-Line, Real-Time Process Gas Analysis. Analytical Chemistry, 74, 3790-3801. http://pubs.acs.org/doi/abs/10.1021/ac0200825

[28] Fan, X., Wei, X.-Y. and Zong, Z.-M. (2013) Application of Gas Chromatography/Mass Spectrometry in Studies on Separation and Identification of Organic Species in Coals. Fuel, 109, 28-32. http://dx.doi.org/10.1016/j.fuel.2012.09.003 
[29] Kong, J., Zhao, R., Bai, Y., Li, G., Zhang, C. and Li, F. (2014) Study on the Formation of Phenols during Coal Flash Pyrolysis Using Pyrolysis-GC/MS. Fuel Processing Technology, 127, 41-46. http://dx.doi.org/10.1016/j.fuproc.2014.06.004

[30] Lu, G.Q. and Do, D.D. (1994) Comparison of Structural Models for High-Ash Char Gasification. Carbon, 32, $247-263$. http://dx.doi.org/10.1016/0008-6223(94)90188-0

[31] Arenillas, A., Rubiera, F. and Pis, J.J. (1999) Simultaneous Thermogravimetric-Mass Spectrometric Study on the Pyrolysis Behavior of Different Rank Coals. Journal of Analytical and Applied Pyrolysis, 50, 31-46. http://dx.doi.org/10.1016/S0165-2370(99)00024-8

[32] Adounkpe, J., Aina, M., Mama, D. and Sinsin, B. (2013) Gas Chromatography Mass Spectrometry Identification of Labile Radicals Formed during Pyrolysis of Catechool, Hydroquinone, and Phenol through Neutral Pyrolysis Product Mass Analysis. ISRN Environmental Chemistry, 2013, 1-8. http://dx.doi.org/10.1155/2013/930573

[33] Kidena, K., Tani, Y., Murata, S. and Nomura, M. (2004) Quantitative Elucidation of Bridge Bonds and Side Chains in Brown Coals. Fuel, 83, 1697-1702. http://dx.doi.org/10.1016/j.fuel.2004.01.021

[34] Borrego, A.G., Alarez, D. and Menendez, R. (1997) Effects of Inertinite Content in Coal on Char Structure and Combustion. Energy and Fuels, 43, 702-761. http://pubs.acs.org/doi/abs/10.1021/ef960130m

[35] Dhaneswar, S.R. and Pisupati, S.V. (2012) Oxy-Fuel Combustion: The Effect of Coal Rank and the Role of $\mathrm{Char}^{-\mathrm{CO}_{2}}$ Reaction. Fuel Processing Technology, 102, 156-165. http://dx.doi.org/10.1016/j.fuproc.2012.04.029 